\title{
Small Size and Low Cost UHF RFID Tag Antenna Mountable on Metallic Objects
}

\author{
Sergio López-Soriano and Josep Parrón \\ Department of Telecommunication and System Engineering, Escola Tècnica Superior d'Enginyeria (ETSE), \\ Universitat Autònoma de Barcelona (UAB), Campus de la UAB, Q Building, Carrer de les Sitges, Bellaterra, \\ Cerdanyola del Vallès, 08193 Barcelona, Spain \\ Correspondence should be addressed to Sergio López-Soriano; sergio.lopez.soriano@uab.es
}

Received 23 July 2015; Revised 9 October 2015; Accepted 12 October 2015

Academic Editor: Ahmed A. Kishk

Copyright (C) 2015 S. López-Soriano and J. Parrón. This is an open access article distributed under the Creative Commons Attribution License, which permits unrestricted use, distribution, and reproduction in any medium, provided the original work is properly cited.

\begin{abstract}
Reducing tag size while maintaining good performance is one of the major challenges in radio-frequency identification applications (RFID), in particular when labeling metallic objects. In this contribution, a small size and low cost tag antenna for identifying metal objects in the European UHF band $(865-868 \mathrm{MHz})$ is presented. The antenna consists of a transmission line mounted on an inexpensive thin dielectric which is proximity-coupled to a short-ended patch mounted on FR4 substrate. The overall dimensions of the tag are $33.5 \times 30 \times 3.1 \mathrm{~mm}$. Experimental results show that, for an EIRP of 3.2 W (European regulations), such a small and cheap tag attains read ranges of about $5 \mathrm{~m}$ when attached to a metallic object.
\end{abstract}

\section{Introduction}

To date, research efforts in the design of UHF RFID tag antennas have been directed toward the following issues: (i) reducing the overall size, (ii) lowering the fabrication costs, and (iii) achieving the specifications of a particular application. In particular, metal-mountable tags have the challenge of achieving read ranges of a few meters with small size and low cost [1].

In the literature, we find several solutions for metalmountable applications: antennas integrating EBG structures [2], antennas using high permittivity materials [3-5], and antennas based on microstrip patch concepts [6-10]. From the viewpoint of cost and manufacturing complexity, this latter group provides the best solution since such designs frequently make use of low cost FR4 dielectric substrate $\left(\varepsilon_{r 1}=\right.$ $4.2, \tan \delta=0.02$, and thickness of $3 \mathrm{~mm}$ ) [6-9]. The area and read range of typical tags are summarized in Table 1.

As might be expected, there is a tradeoff between the area occupied and the read range. We can also see that tags occupying similar area may produce very different read ranges. Therefore, the antenna configuration can make a difference in the tag performance.
In this paper we propose an antenna configuration that comprises a fixed part that determines the behavior of the antenna in terms of radiation and a variable part that can be used to easily match the antenna to the wide variety of integrated circuits (ICs) that can be found in the market. We will show how this configuration can be implemented with low cost materials, resulting in a tag of small size and good performance when placed on metal surfaces.

\section{Antenna Design}

The proposed antenna is illustrated in Figure 1. The patch, which is mounted on FR4 substrate, is designed to operate in a given band and can remain unchanged for different ICs. It has been short-ended in order to reduce the size [11]. Moreover, a slot has been cut in the patch with a view to obtain additional size reduction.

The patch is proximity-coupled to a transmission line which is mounted on an inexpensive thin dielectric. Adjusting the dimensions of the transmission line will slightly modify the input impedance of the antenna, thus making it possible to match it to a particular IC impedance. 


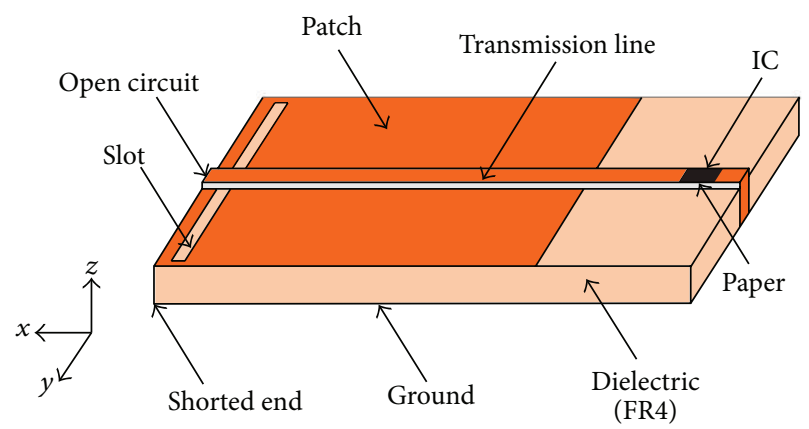

FIGURE 1: Antenna geometry.

TABLE 1: Size and read range for different metal tags that can be found in literature (EIRP: $4 \mathrm{~W}$ ).

\begin{tabular}{lcc}
\hline Reference & Area $\left(\mathrm{mm}^{2}\right)$ & Read range $(\mathrm{m})$ \\
\hline$[6]$ & $32 \times 18$ & 1.5 \\
{$[7]$} & $53 \times 20$ & 2.5 \\
{$[8]$} & $55 \times 22$ & 4.7 \\
{$[9]$} & $68 \times 30$ & 9.5 \\
\hline
\end{tabular}

TABle 2: Prototype dimensions (in $\mathrm{mm}$ ).

\begin{tabular}{lcccccccccc}
\hline$L$ & $L_{p}$ & $L_{\mathrm{tl}}$ & $L_{s 1}$ & $L_{s 2}$ & $g$ & $W$ & $W_{\mathrm{tl}}$ & $W_{s}$ & $h_{1}$ & $h_{2}$ \\
\hline 33.5 & 30.5 & 33.5 & 1 & 1 & 3 & 30 & 1 & 28 & 3.1 & 0.1 \\
\hline
\end{tabular}

The parameters involved in the design are illustrated in Figure 2. A thickness of $3 \mathrm{~mm}\left(h_{1}\right)$ has been selected for the patch substrate for comparison purposes. Regarding the transmission line, it consists of a copper strip which is separated from the patch by a standard paper sheet of thickness $100 \mu \mathrm{m}\left(\varepsilon_{r 2}=3.85\right.$ and $\tan \delta=0.08$ [7] $)$.

The tag has been designed over an infinite ground plane using the simulation software FEKO [12]. The antenna is matched to work with the Alien Higgs-3 integrated circuit [13] $(30-j 211 \Omega$ at $867 \mathrm{MHz})$. Therefore, to obtain the maximum power transfer between the antenna and the IC complex conjugate impedance matching is required. Table 2 summarizes the final dimensions of the tag.

\section{Parametric Study}

In order to justify the election of the final dimensions of the prototype a study on the effects of the main design parameters has been conducted with FEKO to provide a better understanding of the antenna operation. The values in Table 2 will be used as reference dimensions for all simulations. All gain results are given for the $z$-axis direction.

3.1. Radiating Patch. The length of the patch $\left(L_{p}\right)$ controls the resonant frequency of the antenna that roughly corresponds to a quarter of the effective wavelength (Figure 3 ). It is tuned to provide the inductance that compensates the chip capacitance at the operation frequency. As previously commented, a

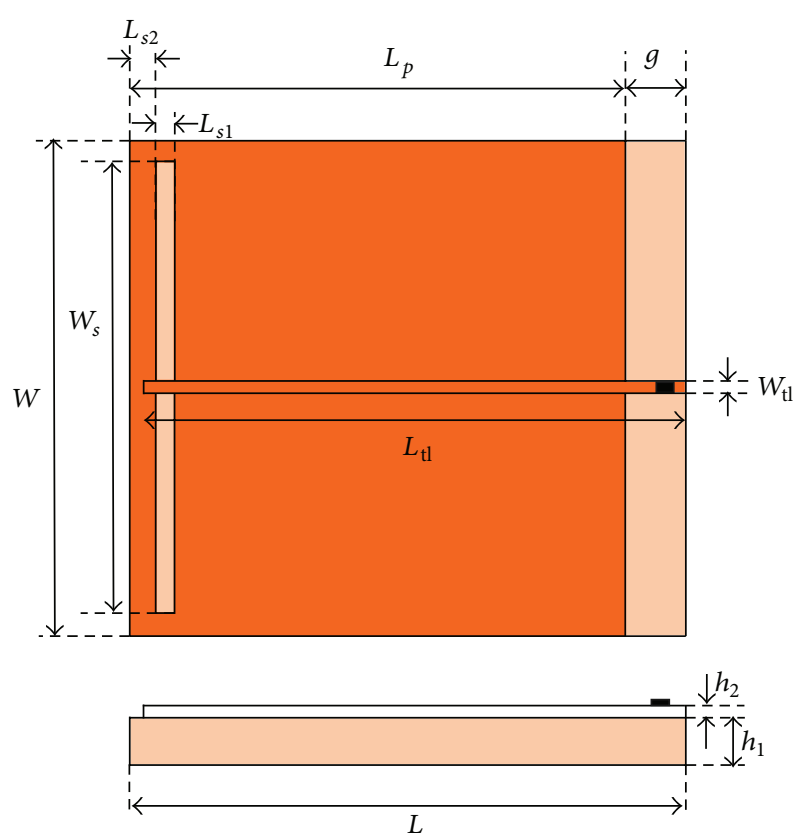

Figure 2: Antenna geometric parameters (top and front view).

slot is cut on the patch thereby increasing its electrical length. This effect is illustrated in Figure 4.

The gap $(g)$, the width $(W)$, and the substrate thickness $\left(h_{1}\right)$ also affect the input impedance of the antenna but we use them to optimize the antenna gain since they also determine the size of the radiating slot of the patch. Figure 5 shows that the thickness is the most relevant parameter for the gain whereas a fine tuning of the gap size (Figure 6) and the width (Figure 7) can provide additional dBs of improvement.

3.2. Feeding Transmission Line. Once the patch has been adjusted to achieve the maximum gain in the desired band, the designer can use the width $\left(W_{\mathrm{tl}}\right)$, length $\left(L_{\mathrm{t} t}\right)$, and thickness $\left(h_{2}\right)$ of the transmission line to match the reactance of different integrated circuits without modifying significantly the gain. Figure 8 shows the range of variation that can be achieved in the input impedance by changing the length whereas Figure 9 shows that the thickness controls the 


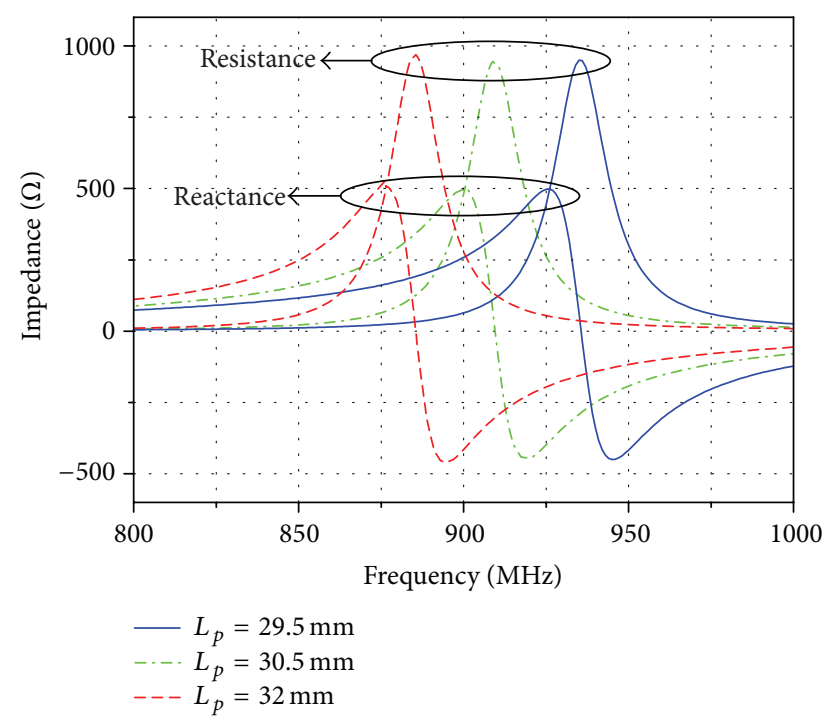

Figure 3: Antenna input impedance for different lengths of the patch.

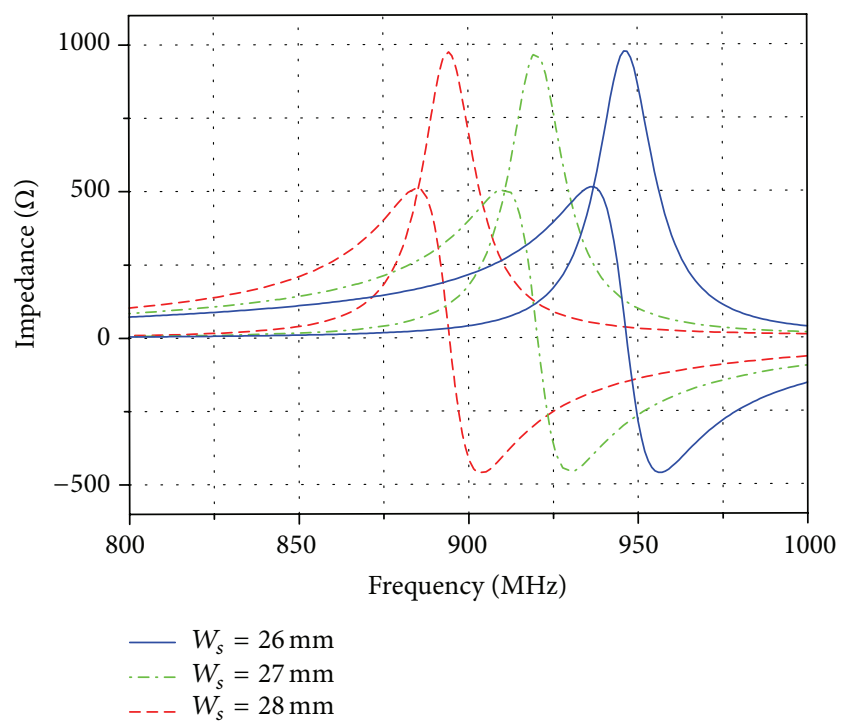

FIGURE 4: Antenna input impedance for different widths of the slot.

coupling between the transmission line and the patch and provides an extra parameter to match the antenna to the IC.

\section{Simulation and Experimental Results}

The fabricated prototype is shown in Figure 10. The IC is easily soldered over the copper strip.

The impedance measurements are conducted over a ground plane of $1 \times 1 \mathrm{~m}^{2}$. The measurement setup is shown in Figure 11. The setup is calibrated at the end of the SMA coaxial cable, and then, an electrical delay of $1.46 \mathrm{~ns}$ is added in order to take into account the effect of the MMCX cable, which was previously characterized.

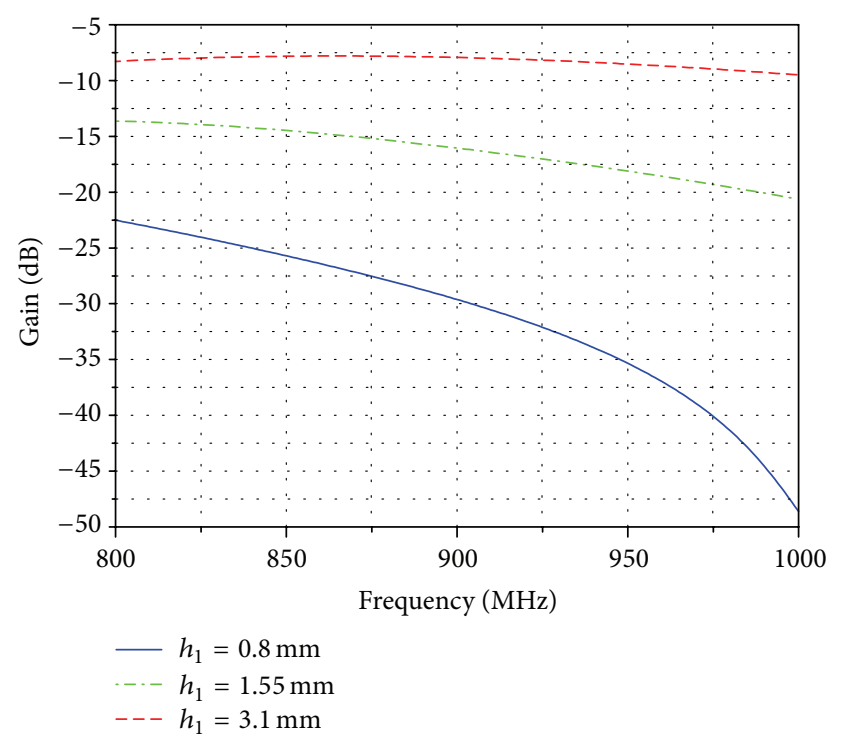

FIGURE 5: Antenna gain for different thicknesses of the patch.

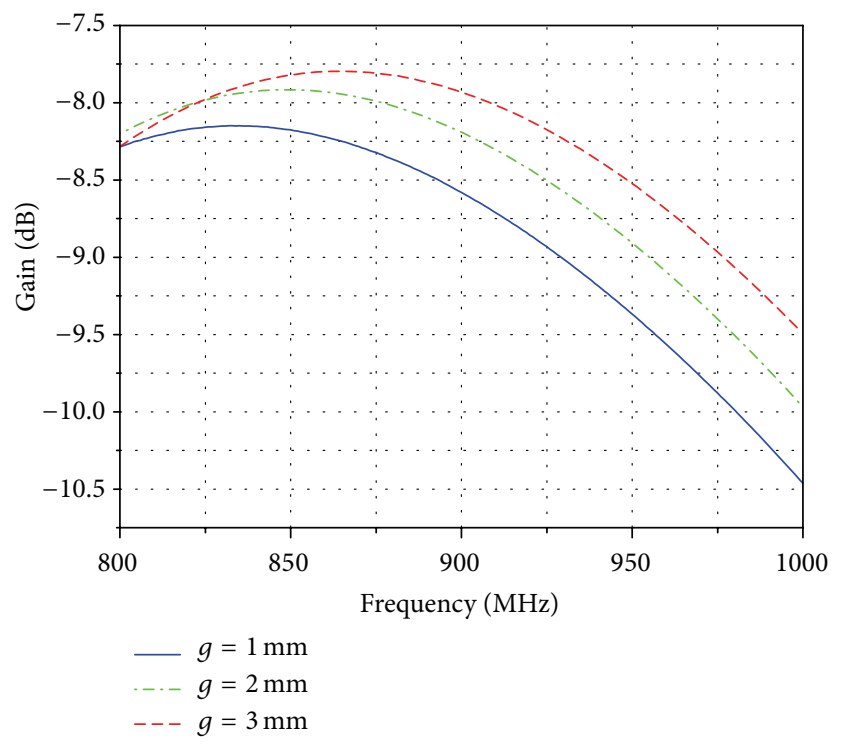

Figure 6: Antenna gain for different sizes of the gap.

Measurements have proven to be repeatable. The measured and simulated input impedance are compared in Figure 12. Despite the slight displacement of the measured reactance, both results are in good agreement.

Figure 13 depicts the simulated radiation pattern of the prototype antenna over a $20 \times 20 \mathrm{~cm}^{2}$ metal plate. As expected, it is similar to a slot oriented along the $y$-axis in a finite ground plane. The maximum gain is $-6 \mathrm{~dB}$ in the $+z$ direction.

The read range measurements have been carried out using the Impinj Speedway Revolution R220 reader [14] and the antenna S8658P from Laird Technologies [15]. The measurement setup is shown in Figure 14.

Although the EIRP for the European standard is $3.2 \mathrm{~W}$, the EIRP was set up to be $4 \mathrm{~W}$ (American standard) in 


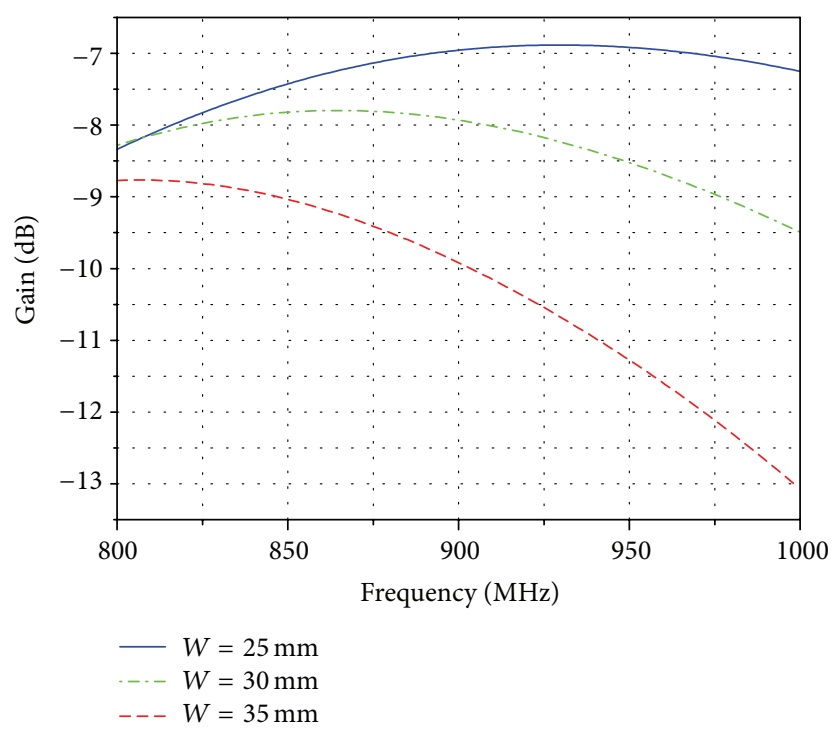

FIGURE 7: Antenna gain for different widths of the patch.

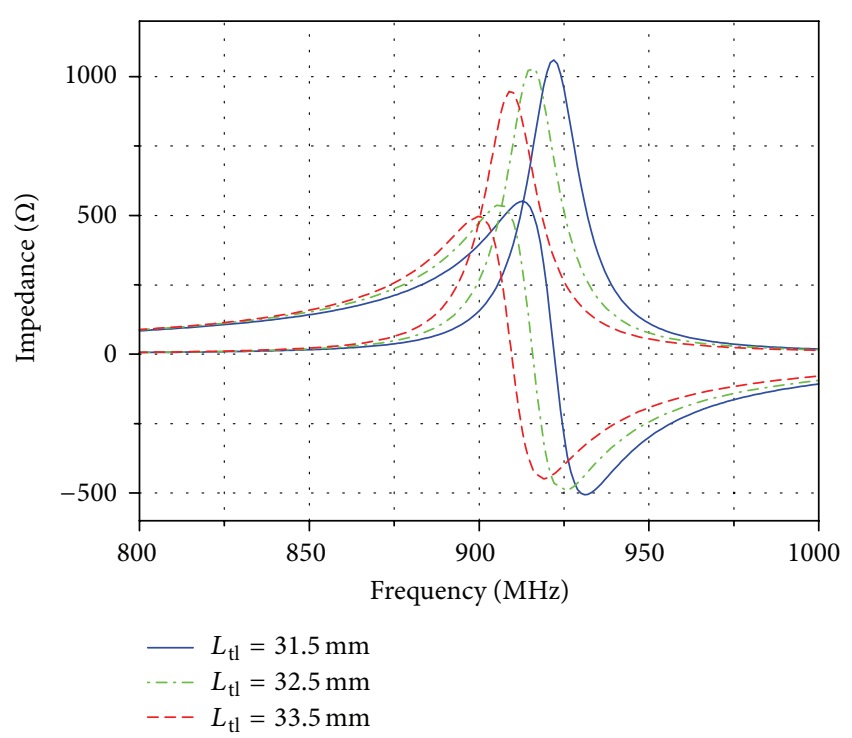

FIGURE 8: Antenna input impedance for different lengths of the transmission line.

order to compare with Table 1. Measurements show that our prototype, placed on top of a $20 \times 20 \mathrm{~cm}^{2}$ metal plate, achieves a read range of $5.6 \mathrm{~m}$; therefore, it improves substantially the read range of some low cost tags that occupy approximately the same area.

The Voyantic Tagformance equipment [16] has also been used to evaluate the read range of our tag with respect to frequency. In this case, the tag has been placed over a metallic box of $15 \times 8 \times 6 \mathrm{~cm}^{2}$. This box modifies slightly the tag performance with respect to $20 \times 20 \mathrm{~cm}^{2}$ metal plate, since the gain is about $1 \mathrm{~dB}$ smaller and the peak of read range is shifted toward upper frequencies (Figure 15).

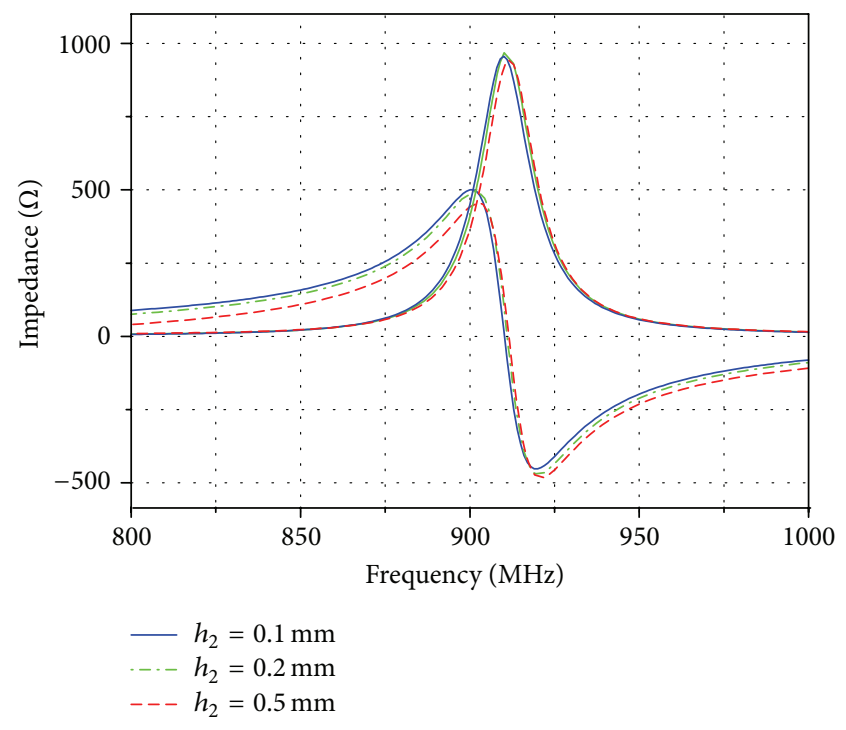

FIGURE 9: Antenna input impedance for different thicknesses of the transmission line.

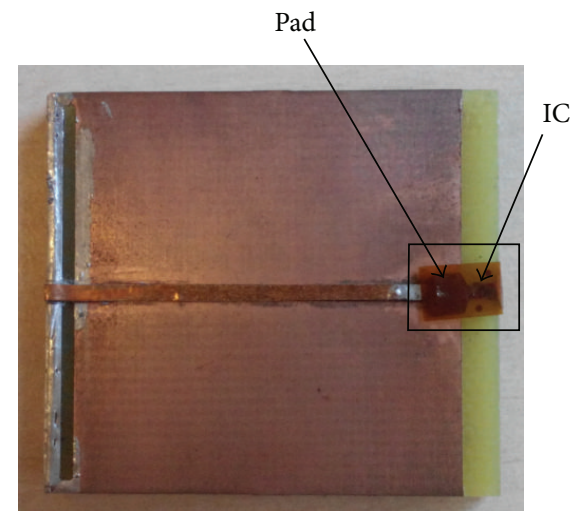

FIGURE 10: Fabricated prototype.

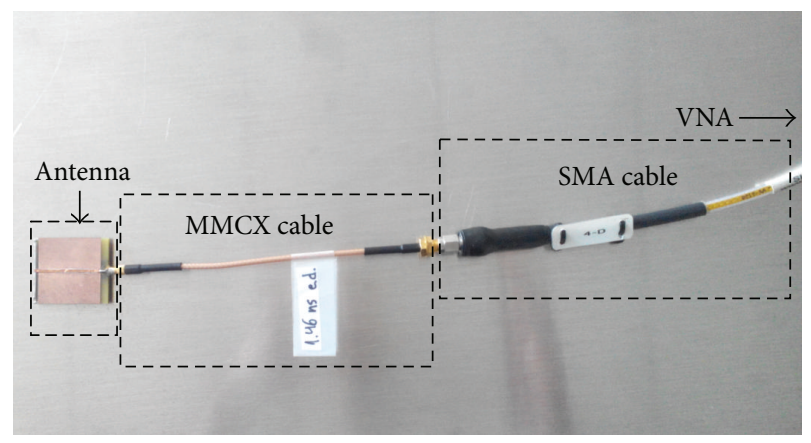

FIGURE 11: Impedance measurement setup.

\section{Conclusions}

The RFID tag presented in this paper is highly suitable for identification of metallic objects and is based on a transmission line that is proximity-coupled to a short-ended patch. The parametric study carried out shows that the radiating 


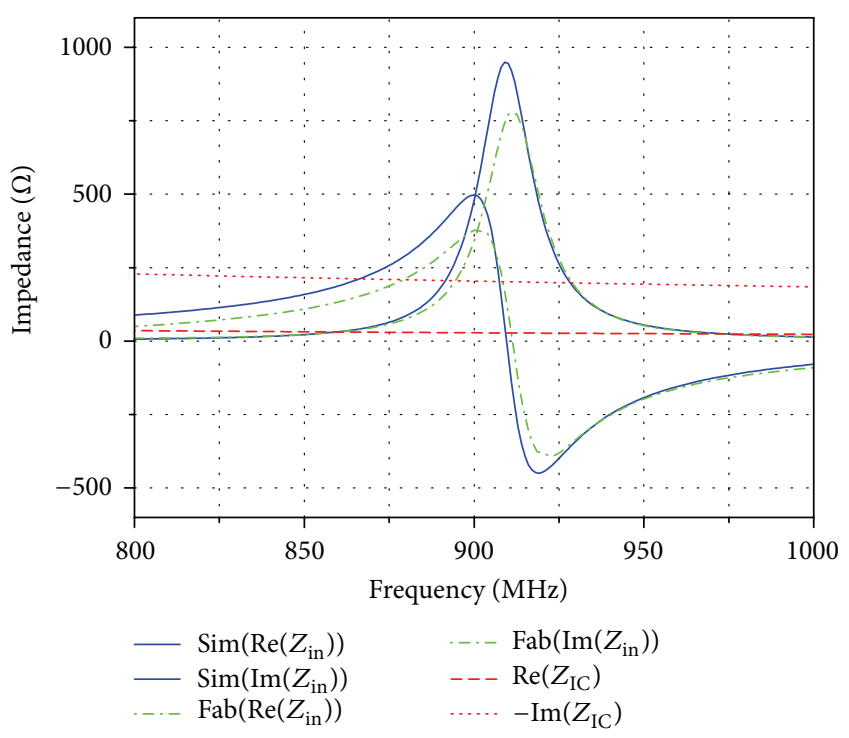

FIGURE 12: Simulated (blue) and measured (green) antenna's input impedance and IC's impedance (red).

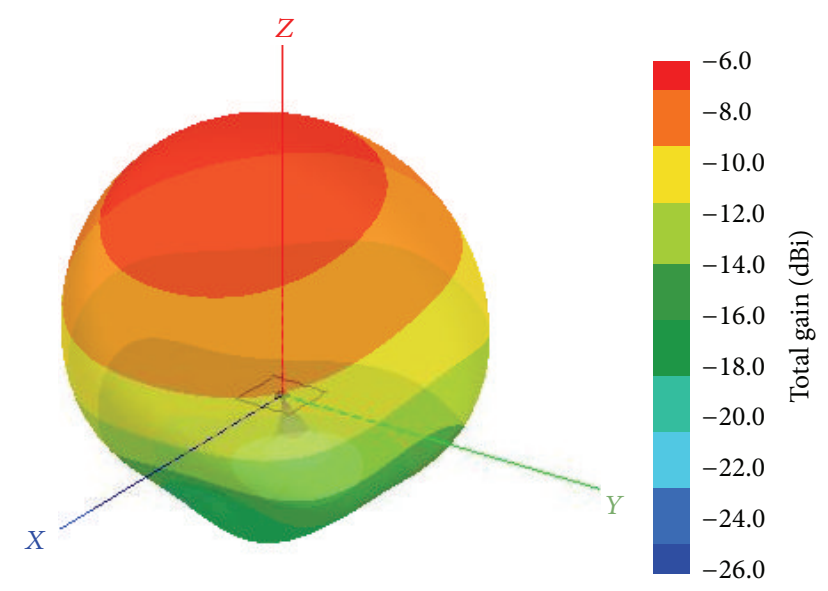

FIGURE 13: Simulated radiation pattern for a $20 \times 20 \mathrm{~cm}^{2}$ metal plate.

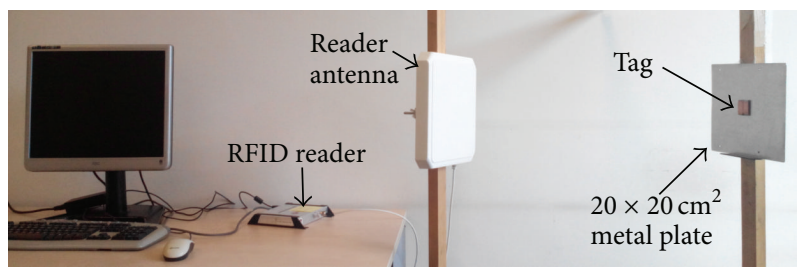

FIGURE 14: Read range measurement setup.

patch can be optimized to achieve the maximum gain in the desired band while the feeding transmission line can be easily tuned to match different integrated circuits.

The proposed tag has been made of inexpensive materials with a simple and repeatable procedure and has dimensions of $33.5 \times 30 \times 3.1 \mathrm{~mm}$. The read range of the tag has proven to be significantly better than other solutions that can be found in literature with approximately the same area $[7,8]$.

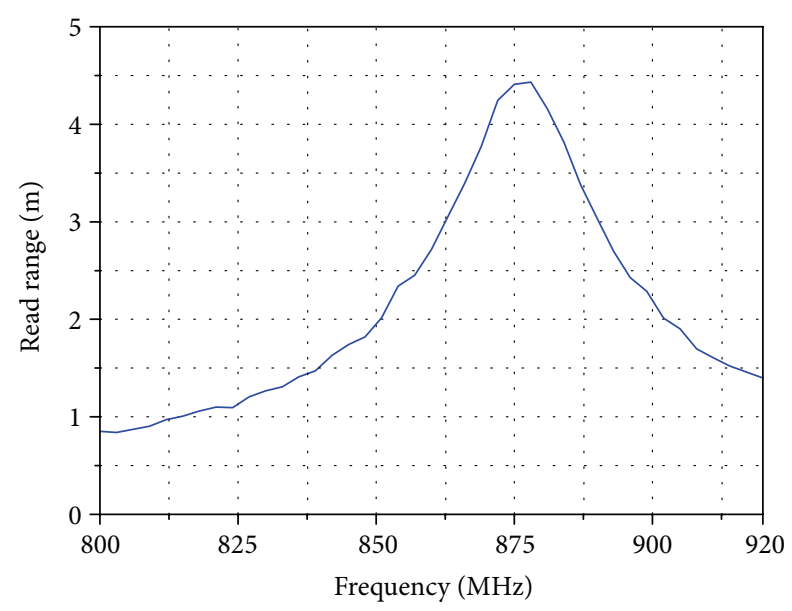

FIGURE 15: Voyantic read range measurement.

\section{Conflict of Interests}

The authors declare that there is no conflict of interests regarding the publication of this paper.

\section{Acknowledgments}

This work was supported by the Universitat Autònoma de Barcelona and the Spanish Ministry of Economy and Competitiveness through Project TEC2012-37582-C04-01 and FEDER funds.

\section{References}

[1] T. Björninen, L. Sydänheimo, L. Ukkonen, and Y. RahmatSamii, "Advances in antenna designs for UHF RFID tags mountable on conductive items," IEEE Antennas and Propagation Magazine, vol. 56, no. 1, pp. 79-103, 2014.

[2] B. Gao and M. M. F. Yuen, "Passive UHF RFID packaging with electromagnetic band gap (EBG) material for metallic objects tracking," IEEE Transactions on Components, Packaging and Manufacturing Technology, vol. 1, no. 8, pp. 1140-1146, 2011.

[3] A. A. Babar, T. Björninen, V. A. Bhagavati, L. Sydänheimo, P. Kallio, and L. Ukkonen, "Small and flexible metal mountable passive UHF RFID tag on high-dielectric polymer-ceramic composite substrate," IEEE Antennas and Wireless Propagation Letters, vol. 11, pp. 1319-1322, 2012.

[4] A. A. Babar, J. Virtanen, V. A. Bhagavati et al., "Inkjetprintable UHF RFID tag antenna on a flexible ceramic-polymer composite substrate," in Proceedings of the IEEE MTT-S International Microwave Symposium Digest (MTT '12), pp. 1-3, IEEE, Montreal, Canada, June 2012.

[5] J.-S. Kim, W.-K. Choi, and G.-Y. Choi, "Small proximity coupled ceramic patch antenna for UHF RFID tag mountable on metallic objects," Progress in Electromagnetic Research C, vol. 4, pp. 129-138, 2008.

[6] S.-L. Chen, "A miniature RFID tag antenna design for metallic objects application," IEEE Antennas and Wireless Propagation Letters, vol. 8, pp. 1043-1045, 2009.

[7] P. H. Yang, Y. Li, L. Jiang, W. C. Chew, and T. T. Ye, "Compact metallic RFID tag antennas with a loop-fed method," IEEE 
Transactions on Antennas and Propagation, vol. 59, no. 12, pp. 4454-4462, 2011.

[8] L. Mo and C. Qin, "Tunable compact UHF RFID metal tag based on CPW open stub feed PIFA antenna," International Journal of Antennas and Propagation, vol. 2012, Article ID 167658, 8 pages, 2012.

[9] K.-H. Lin, S.-L. Chen, and R. Mittra, "A looped-bowtie RFID tag antenna design for metallic objects," IEEE Transactions on Antennas and Propagation, vol. 61, no. 2, pp. 499-505, 2013.

[10] Xerafy: Mercury Metal Skin Inlay, http://www.xerafy.com/ catalogue/product/metal-skin-inlay/l.

[11] P. Mirchandani, K. Deshpande, and R. Khan, "Performance analysis of miniaturized microstrip patch antennas for UHF RFID applications," in Proceedings of the International Conference on Signal Processing, Communication, Computing and Networking Technologies (ICSCCN '11), pp. 244-249, IEEE, Thuckalay, India, July 2011.

[12] FEKO EM Simulation software, http://www.feko.info.

[13] Alien Technology Corporation, Higgs-3 product brief, http:// www.alinetechnology.com/ic/higgs-3.

[14] Impinj, Speedway Revolution R220, http://www.impinj.com/ products/speedway/speedway-revolution-rfid-readers/.

[15] Laird Technologies, S8658P, http://www.lairdtech.com/products/s8658pr.

[16] Voyantic Tagformance, https://voyantic.com/tagformance. 

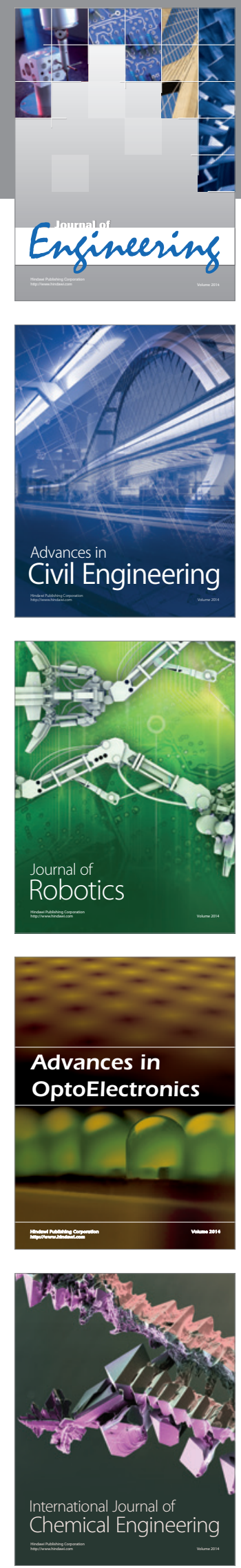

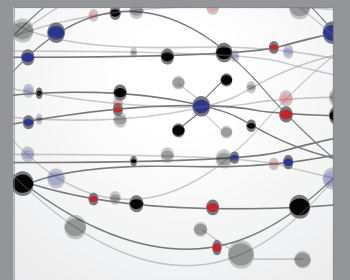

The Scientific World Journal
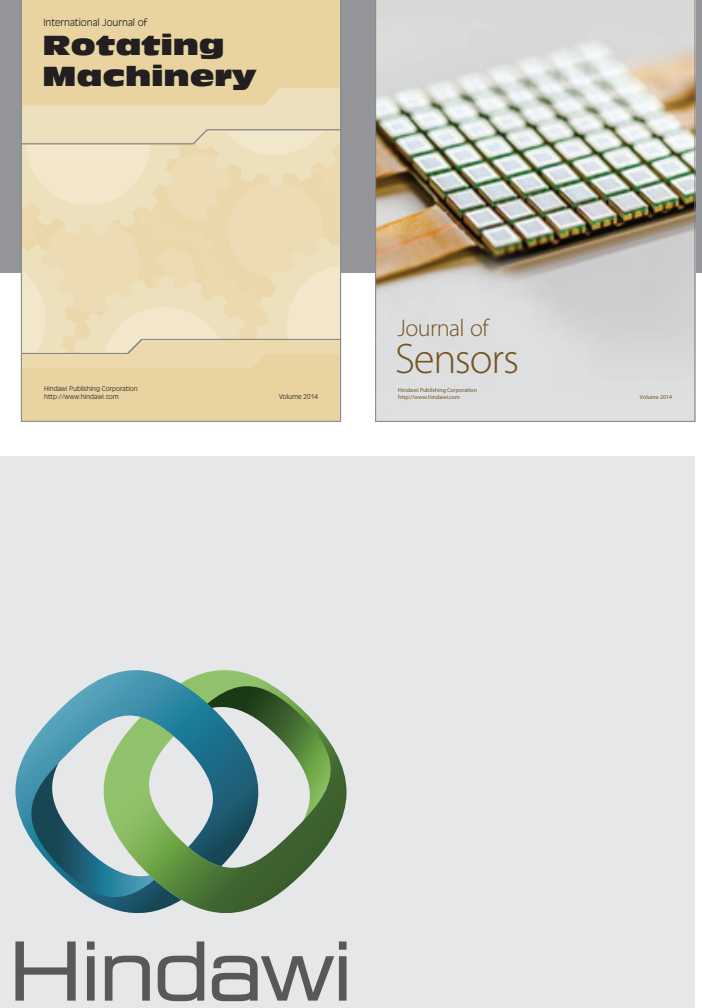

Submit your manuscripts at http://www.hindawi.com
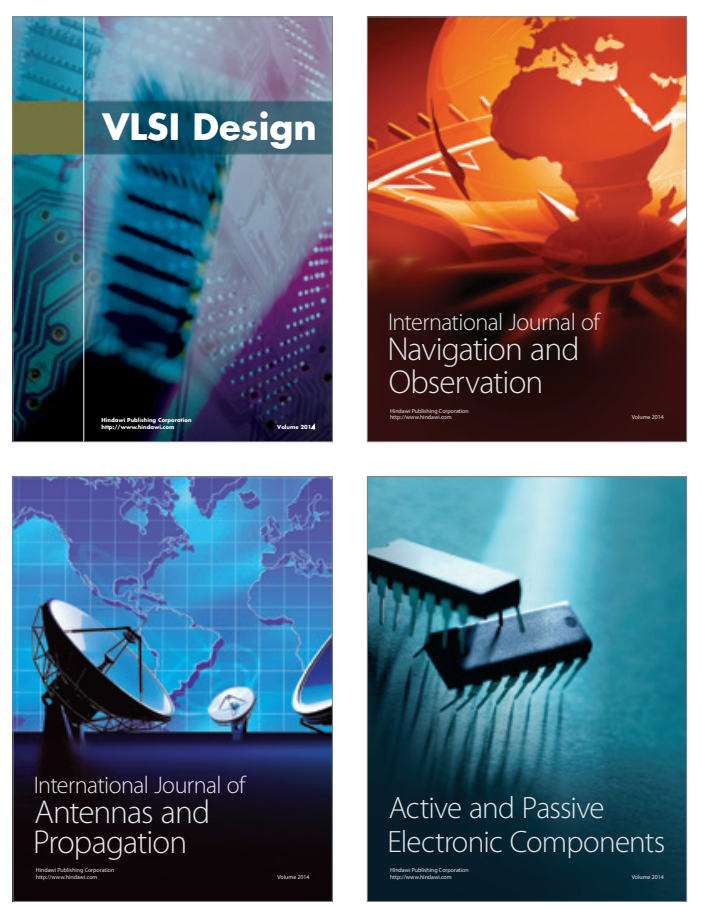
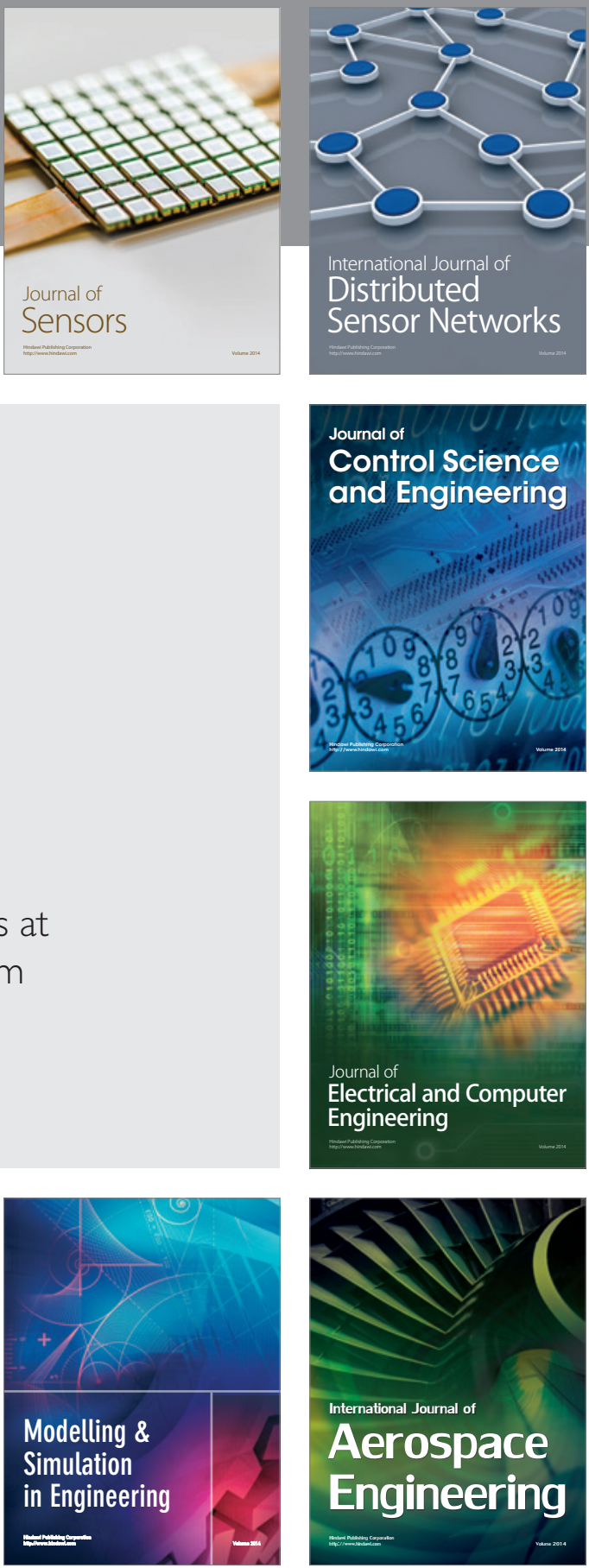

Journal of

Control Science

and Engineering
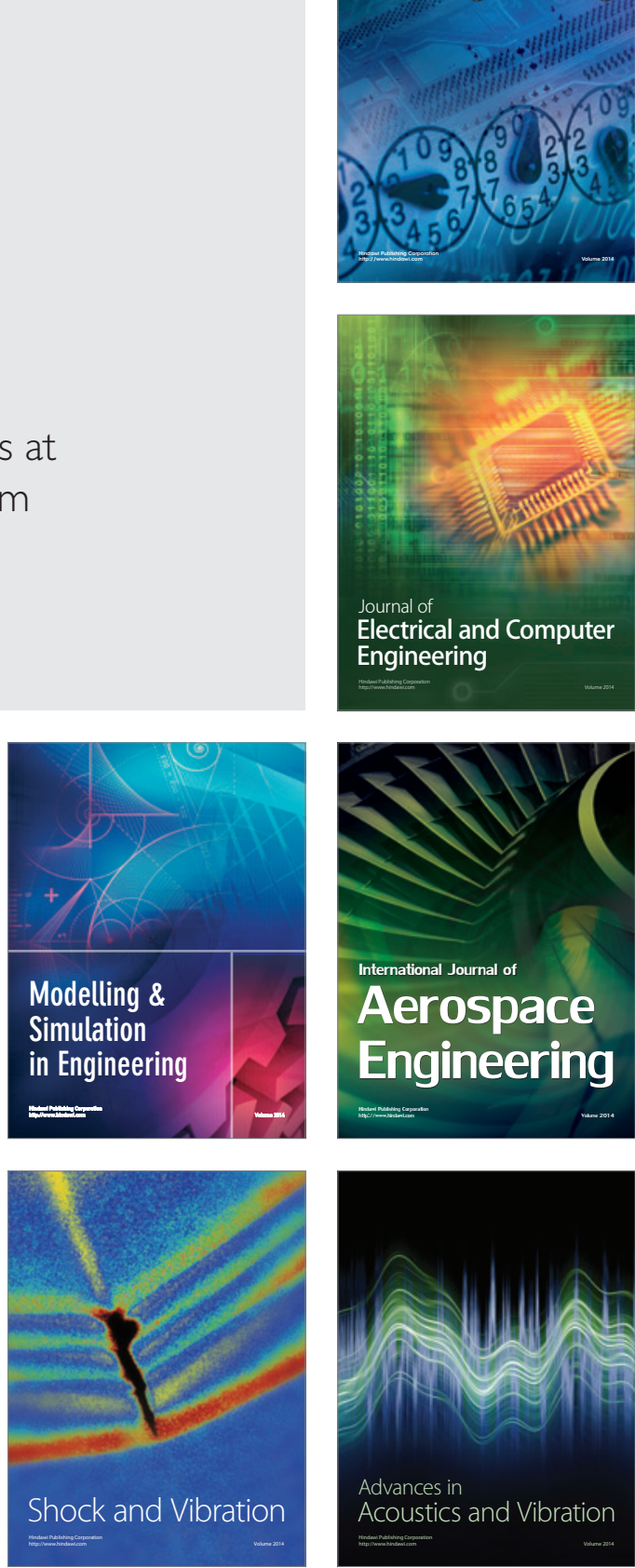